\title{
Oral cefuroxime axetil compared with oral ampicillin in treating acute uncomplicated gonorrhoea
}

\author{
T M WANAS* AND P E O WILLIAMS $\dagger$ \\ From the *Department of Genitourinary Medicine, Royal Hospital, Wolverhampton, West Midlands and \\ † Glaxo Group Research Ltd, Greenford, Middlesex
}

SUMMARY The efficacy and tolerance of single oral doses of cefuroxime axetil $(1.5 \mathrm{~g})$ were compared with oral ampicillin $(3 \mathrm{~g})$ for treating acute gonococcal urethritis in 110 men and 30 women. Each dose was given with $1 \mathrm{~g}$ probenecid.

Of the 62 assessable patients who received ampicillin, two failed to respond to treatment. Of 67 assessable patients who received cefuroxime axetil, one failed to respond.

Pencillinase producing strains of Neisseria gonorrhoeae were isolated from five patients; one received ampicillin and failed to respond, whereas the other four received cefuroxime axetil and three were cured.

A single oral dose of $1.5 \mathrm{~g}$ cefuroxime axetil with $1 \mathrm{~g}$ probenecid seemed to be an effective treatment for acute gonococcal urethritis, especially for penicillin resistant strains.

\section{Introduction}

Several studies have shown that cefuroxime is effective in the treatment of gonorrhoea caused both by strains of Neisseria gonorrhoeae that do not produce $\beta$ lactamase and those that do. ${ }^{1-3}$ Cefuroxime axetil is an ester prodrug of cefuroxime and is well absorbed after oral administration. The ester linkage in cefuroxime axetil is presumed to be hydrolysed in the intestinal mucosa during absorption, as only cefuroxime was detected in the peripheral circulation of volunteers. ${ }^{4}$ The activity of cefuroxime against $N$ gonorrhoeae combined with the pharmacokinetic properties of the prodrug have suggested that cefuroxime axetil would be an effective oral treatment for acute gonococcal urethritis.

We report a study of the efficacy and tolerance of single oral doses of cefuroxime axetil compared with oral ampicillin for treating acute uncomplicated gonorrhoea in men and women.

Address for reprints: Dr T M Wanas, Department of Genitourinary Medicine, Royal Hospital, Cleveland Road, Wolverhampton, West Midlands

Accepted for publication 19 December 1985

\section{Patients and methods}

We studied men and women outpatients who attended the department of genitourinary medicine, Royal Hospital, Wolverhampton, who showed clinical signs and symptoms consistent with a diagnosis of gonococcal infection or were the female sexual contacts of infected men. Allergy to penicillins or cephalosporins, requirement for concurrent antibiotics, and suppressive antimicrobial treatment within the four weeks preceeding the study were all reasons for exclusion. All pregnant or lactating women were excluded as was any patient who was thought to be unlikely to return for follow up visits. The study protocol was approved by the hospital ethics review committee, and informed consent was obtained from all patients.

On attendance at the clinic, the symptoms and clinical findings were noted, and smears were taken from the urethra and cervix. Rectal smears were taken from male homosexuals and from female partners of men with gonorrhoea. Smears were examined microscopically for the detection of $\mathrm{Ngonorrhoeae}$ as Gram negative intracellular diplococci. Materials from the same anatomical sites (and the pharynx when indicated) were cultured for $N$ gonorrhoeae on modified Thayer-Martin medium. Two glass urine tests 
were performed. Urethral material from men was examined for the presence of Chlamydia trachomatis using McCoy cell culture.

Disc sensitives to cefuroxime penicillin, and ampicillin were measured for all gonococcal isolates, and a nitrocefin test was performed on those showing resistance to penicillin. A blood specimen was taken from each patient for serological tests for syphilis.

Patients were randomly allocated to receive a single oral dose of $1.5 \mathrm{~g}$ cefuroxime axetil (equivalent to $1.5 \mathrm{~g}$ cefuroxime as the acetoxyethyl ester) with $1 \mathrm{~g}$ probenecid or $3 \mathrm{~g}$ ampicillin with $1 \mathrm{~g}$ probenecid. Separate random allocations were used in the clinics for men and women. Patients were asked to abstain from alcohol and sexual intercourse and return seven and 14 days later.

At the second attendance (first follow up) the patients were asked about symptoms, sexual contacts since their first visit, and adverse reactions (whether related to the drug or not) that had occurred after the treatment. Material for microscopy and culture was taken from the previously infected sites and a two glass urine test was taken. The same schedule was followed at the third visit.

Clinical assessment was made at the first follow up visit. Cure was defined by negative findings on both microscopy and culture. Failure was defined by persistence of gonococci on microscopy or culture, or both, at any initially infected site. Patients were excluded from the comparison of efficacy if they did not return for the first follow up visit, they had had sexual contact with untreated partners and the evidence from contact tracing supported the view that these patients had probably been reinfected, or they had concurrent primary syphilis.

At the second follow up visit, assessable patients whose urethral discharge had persisted or recurred after the eradication of gonorrhoea were diagnosed as having postgonococcal urethritis if microscopy of the urethral exudate showed more than five leucocytes per high power field and the urine contained floccules.

Fisher's exact test was used to analyse two by two contingency tables. ${ }^{5}$ If the probability of the test result was less than $5 \%(p<0.05)$, it was regarded as significant. As each treatment group contained 70 patients, the study had $76 \%$ ability to detect whether cefuroxime axetil had a clinical efficacy $5 \%$ worse than ampicillin if the efficacy of ampicillin was $100 \%$.

\section{Results}

In all, 110 men and 30 women entered the trial. The treatment groups were well matched for age. The mean (range) age of patients treated with cefuroxime axetil was 23 (16-42) years and of those treated with ampicillin 21 (18-25) years. The groups were also well matched for sites of infection. Of the 110 men, 105 had urethral gonorrhoea only; 51/55 of those receiving cefuroxime axetil and $54 / 55$ of those receiving ampicillin. Two patients, one man and one woman, had had unsuccessful antimicrobial treatment with intramuscular penicillin before entering to the trial, and both were found to be infected with penicillinase producing $N$ gonorrhoeae (PPNG) strains. The random allocation was modified, and these two patients were given cefuroxime axetil.

The table shows the numbers of patients cured in each treatment group. Of the men, five did not return for the first follow up visit, and at the first follow up one was found to have concurrent syphilis, which was treated during the following week, and two had been reinfected during the week after treatment. Of the women, two did not return and one had been reinfected. In all, 67 patients given cefuroxime axetil and 62 given ampicillin were assessed at the first follow up visit. A further 18 patients failed to return for the

TABLE Attendances at two follow up visits and cures of gonorrhoea in 140 patients

\begin{tabular}{|c|c|c|c|c|}
\hline & \multicolumn{4}{|c|}{ No (\%) treated with: } \\
\hline & \multicolumn{2}{|c|}{ Cefuroxime axetil } & \multicolumn{2}{|l|}{ Ampicillin } \\
\hline & $\begin{array}{l}\text { Men } \\
(n=55)\end{array}$ & $\begin{array}{l}\text { Women } \\
(n=15)\end{array}$ & $\begin{array}{l}M e n \\
(n=55)\end{array}$ & $\begin{array}{l}\text { Women } \\
(n=15)\end{array}$ \\
\hline $\begin{array}{l}\text { Attending first follow up } \\
\text { Asessable at first follow up } \\
\text { Cured at first follow up } \\
\text { Assessable patients with urethral } \\
\text { gonorrhoea only }\end{array}$ & $\begin{array}{l}53(96.4) \\
53(96.4) \\
53(96 \cdot 4) \\
50(90.9)\end{array}$ & $\begin{array}{l}15(100) \\
14 *(93 \cdot 3) \\
13(86 \cdot 7) \\
11(73 \cdot 3)\end{array}$ & $\begin{array}{l}52(94 \cdot 5) \\
49(89 \cdot 1) \\
48(87 \cdot 3) \\
49(89 \cdot 1)\end{array}$ & $\begin{array}{l}13(86 \cdot 7) \\
13(86 \cdot 7) \\
12(80) \\
12(80)\end{array}$ \\
\hline $\begin{array}{l}\text { Urethral gonorrhoea cured } \\
\text { Attending second follow up } \\
\text { Cured at second follow up }\end{array}$ & $\begin{array}{l}50(90 \cdot 9) \\
47(85 \cdot 5) \\
47(85 \cdot 5)\end{array}$ & $\begin{array}{l}11(73 \cdot 3) \\
13(86 \cdot 7) \\
12(80)\end{array}$ & $\begin{array}{l}48(87 \cdot 3) \\
43(78 \cdot 2) \\
41(74 \cdot 5)\end{array}$ & $\begin{array}{l}11(73 \cdot 3) \\
12(80) \\
11(73 \cdot 3)\end{array}$ \\
\hline
\end{tabular}

* One patient had persistent pharyngeal gonorrhoea but cured concurrent rectal and cervical gonorrhoea, all others were cured. 
second follow up visit, but were assessed on the results at the first follow up.

Gonorrhoea was cured in $66(98.5 \%)$ of 67 assessable patients given cefuroxime axetil. In one woman, infection in the pharynx persisted, though the rectal and cervical cultures were negative. Of the 62 assessable patients given ampicillin, treatment of urethral gonorrhoea failed in two, giving a cure rate of $96.8 \%$. If only urethral gonorrhoea is considered, the respective cure rates were $100 \%(61 / 61)$ for those given cefuroxime axetil and $96.7 \%(59 / 61)$ for those given ampicillin. The differences in clinical response between the two groups were not significant.

Five patients were infected with PPNG strains. One was treated unsuccessfully with ampicillin, and of the other four patients who each received cefuroxime axetil, three were cured. The failure after cefuroxime axetil was in the patient described above who had persistent pharyngeal gonorrhoea. Three of the patients given cefuroxime should have received ampicillin according to the random allocation, but they were known to be sexual contacts of carriers of PPNG strains and so the code was broken before treatment.

Chlamydiae were detected at the first visit in 12 out of 55 men given ampicillin and six men given cefuroxime axetil (no significant difference by Fisher's exact test). Postgonococcal urethritis, however, was found at the second visit in $30(54 \%)$ men given ampicillin and 19 (34\%) men given cefuroxime axetil, which was a significant difference between drugs $(p<0.05)$. The women were not tested for chlamydiae.

Both cefuroxime axetil and ampicillin were well tolerated. The only adverse events that we thought were related to ampicillin occurred in two women, one of whom developed generalised itching and the other vomited four hours after treatment. After receiving cefuroxime axetil two men and one woman had minor transient gastrointestinal disturbances.

\section{Discussion}

Cefuroxime axetil, an oral prodrug of cefuroxime, was compared with ampicillin for the treatment of acute uncomplicated gonorrhoea in 110 men and 30 women. The dose of ampicillin $(3 \mathrm{~g})$ was that recommended by the Food and Drug Administration guidelines. The dose of cefuroxime axetil $(1.5 \mathrm{~g})$ has been shown to give a serum concentration of cefuroxime above the minimum inhibitory concentration for $90 \%$ of strains of $\mathbf{N g o n o r r h o e a e}$ for 14 hours when combined with $1 \mathrm{~g}$ probenecid (data on file, Glaxo Group Research).

Of the 140 patients studied, 129 (92\%) were assessable both clinically and bacteriologically, which is a higher rate of assessibility than those reported by Fowler $e t a l^{l}$ and by Lossick et $a L^{3}$ The cure rates in the treatment of urethral gonorrhoea were $100 \%$ for cefuroxime axetil and $96 \cdot 7 \%$ for ampicillin. Insufficient numbers of patients had infections at sites other than the cervix in women or the urethra in either sex for us to draw useful conclusions about the efficacy of the drugs against pharyngeal or rectal gonorrhoea.

Cefuroxime axetil was effective in three out of four patients infected with PPNG strains, in that infected sites were cleared in three patients and concurrent pharyngeal gonorrheoa persisted in one patient. Clearance of pharyngeal gonorrhoea might not be expected after a single oral dose of an antibiotic as more intensive treatment is recommended for pharyngeal infection. ${ }^{6}$

Chlamydiae were isolated from more patients given ampicillin, and more cases of postgonococcal urethritis were found in that group. The aetiology of postgonococcal urethritis is not completely understood, so higher incidence after receiving ampicillin may have been related to undetectable pathogens.

Adverse events did not represent a great problem in this study, but larger numbers of patients would be needed to give a definitive assessment of comparative tolerances to cefuroxime axetil and ampicillin in single large doses.

As the prevalence of PPNG strains increases, ${ }^{7-9}$ the need for $\beta$ lactamase stable antibiotics increases in parallel. Cefuroxime axetil is one such antibiotic, which should prove both effective in treating PPNG strains and useful if it is competitively priced in comparison with other drugs. Furthermore, cefuroxime axetil has the considerable advantage of being an oral drug.

We thank staff of the department of genitourinary medicine and the serology laboratory of the Royal Hospital for their technical help and Mrs J A Forkes for her help with data handling.

\section{References}

1. Fowler W, Rahim G, Brown JD. Clinical experience in the use of cefuroxime in gonorrhoea. British Journal of Venereal Diseases 1978;54:400-2.

2. Morrison GD, Evans AJ, Haskins HW, et al. Cefuroxime compared to penicillin for the treatment of gonorrhea. Sex Transm Dis 1980;7:188-90.

3. Lossick JE, Thompson ES, Smeltzer MP. Comparison of cefuroxime and penicillin in the treatment of uncomplicated gonorrhoea. Antimicrob Agents Chemother 1982;22:409-13.

4. Harding SM, Williams PO, Ayrton J. Studies on the parmacology of cefuroxime axetil (cefuroxime as the 1-acetoxyethyl ester) in volunteers. Antimicrob Agents Chemother 1984; 25:78-82.

5. Bailey NTJ. Statistical methods in biology. London: English Universities Press, 1974.

6. Platts MW. In: Avery GS, ed. Drug treatment. Sydney: Adis Press, 1980

7. McCutchan JA, Adler MW, Berrie JRH. Penicillinase producing Neisseria gonorrhoeae in Great Britain, 1977-82; alarming increase in incidence and recent development of endemic transmission. Br Med J 1982:28:337-40.

8. Jaffe HW, Biddle JW, Johnson SR, Wiesner PJ. Infections due to penicillianse-producing Neisseria gonorrhoeae in the United States, 1976-80. J Infect Dis 1981;144:191-7.

9. Van Embden JDA, Van Klingeren B, Dessens-Kroon M, Van Wijngaarden $\mathrm{LJ}$. Emergence in the Netherlands of penicillinase producing gonococci carrying "Africa" plasmid in combination with transfer plasmid. Lancet 1981;i:938. 